\title{
Open Voice or Private Message? The Hidden Tug-of-War on Social Media Customer Service
}

\author{
Shu $\mathrm{He}$ \\ University of Connecticut \\ shu.he@uconn.edu
}

\author{
Shun-Yang Lee \\ University of Connecticut \\ shun-yang.lee@uconn.edu
}

\author{
Huaxia Rui \\ University of Rochester \\ huaxia.rui@simon.rochester.edu
}

\begin{abstract}
We study customers' and brands' preferences towards public and private customer service interactions on social media. Using a natural experiment where the ease of private communication with a brand is exogenously and significantly increased, we found that complaining customers prefer to do so publicly while some non-complaining customers prefer to communicate privately. However, through a randomized field experiment, we found that firms prioritize complaints received from the private channel over complaints received from the public channel. Therefore, brands, well aware of the risk of subjecting its customer service under public scrutiny, prefer complaints communicated privately and seem to nudge customers towards switching back to the traditional mode of customer service where all interactions are private. The divergent preferences towards open voice and private message suggest a hidden tug of war between the traditional delivery of customer service featuring brand control and social media customer service featuring transparency and openness.
\end{abstract}

\section{Introduction}

How do we respond when the perceived quality of a good or service is below our expectation? Hirschman [15] argues that there are essentially two responses: exit, that is, to discontinue the relation, or voice, that is, to repair through the communication of complaint or proposal for change. Hirschman's theory of exit and voice provides a unifying conceptual framework to understanding economic and political actions people may take when something goes wrong with the operation of an organization. To reduce exits, it is crucial that customers or the public can easily communicate their complaints and suggestions. Therefore, delivering customer service or offering people a voicing channel has always been an essential part of any business in a market economy or any government in a democratic society.

Conceptually, we can further distinguish two types of voices: private voice, which refers to voices solely communicated with the responsible party and not visible to the general public, and public voice, which refers to voices communicated with the responsible party but also visible to the general public. Unlike the political context where public voicing and debate is common, most of the customer service interaction in the business context is private, whether the customer service is delivered in person, by phone, through email, or more recently, via chatbot. This distinction, however, is starting to disappear with the emergence of social media customer service. Nowadays, companies routinely respond to and sometimes address customer complaints publicly on social media platforms such as Facebook and Twitter [14]. For example, on Twitter, a disgruntled customer can publicly complain to a brand by mentioning the official account name of a brand with the symbol @. The brand typically replies to the customer publicly on Twitter as well. If there is a need to exchange sensitive information, they can use direct message (i.e., DM) on Twitter to communicate privately.

From the perspective of customers, the new option of publicly complaining to a brand clearly empowers them, especially for those with large social media influence. Indeed, there are reports that dissatisfied customers only had their issues resolved after they switched from the traditional customer service via phone line to the social media customer service. ${ }^{1}$ Moreover, social psychology theory suggests that when people perceive themselves as being treated unfairly, there is an inherent need to restore the emotional balance [9]. Publicly venting about the brand is often an effective and efficient way of achieving such a balance. Given these benefits, we conjecture that customers who complain through social media will prefer to voice publicly. On the other hand, for customers who merely seek some information from the firm, it is possible that

\footnotetext{
${ }^{1}$ Source: http://time.com/3916355/social-media-customer-service/ (Last access: Aug 27th, 2018)
} 
some of them prefer the private channel because of the comfort of privacy. To evaluate these conjectures, we use a natural experiment (from the perspective of customers) in 2016 when Delta Air Lines adopted OpenDM on Twitter, a new feature that allows anyone to send a private message to Delta Air Lines on Twitter without first being followed by or following Delta. To Delta's customers, this sudden availability of OpenDM exogenously and dramatically increased the ease of using private channel to communicate their complaints. Indeed, with OpenDM, there is no real difference in terms of the convenience between complaining publicly on Twitter or privately through direct message. If all customers who complain to the brand on social media prefer to do so publicly, we should not expect any statistically significant drop in the number of public complaints after the adoption of OpenDM, everything else equal. On the other hand, if some non-complaining customers (e.g., information seeking) prefer to communicate privately with the brand, we should expect a statistically significant drop in the number of noncomplaints communicated to the brand publicly, everything else equal. To summarize, we propose the following two hypotheses for empirical testing:

Hypothesis 1A: There is no statistically significant change in the number of publicly communicated complaints before and after the adoption of OpenDM, everything else equal.

Hypothesis 1B: There is a drop in the number of publicly communicated non-complaints after the adoption of OpenDM, everything else equal.

The clear benefits for consumers to have this public customer service channel, aided by the ubiquity of smart phones and social media technology, perhaps explains the growing popularity of firms delivering customer service through social media platforms such as Twitter and Facebook. However, from a brand's perspective, there are both direct benefits and risk associated with this new customer service channel. By publicly responding to a complaining customer, rather than ignoring the complaint, the brand is publicly demonstrating its willingness and effort to correct its mistake, which may potentially serve as a positive marketing message. However, by subjecting its customer service under public scrutiny, the brand also risks failing to respond to or address a complaint publicly, which may further trigger additional complaints and criticisms. Recent research suggests that most customers who received customer service through social media actually felt the same or worse after their interactions with the brand [12]. Hence, it is likely that for a typical brand, the risk of delivering customer service on social media outweighs the direct benefit of doing so, but shunning away from this new channel is likely an even worse strategy because the avoidance can signal the brand's lack of confidence or openness, especially if its competitors or firms in other industries are already delivering customer service via social media. Given this dilemma, we conjecture that firms will prefer to deliver social media customer service as privately as possible. For example, on Twitter, firms may promote or incentivize, directly or indirectly, the use of direct messaging for customers to voice their complaints. By keeping complaints and conversations private, firms essentially turn social media customer service into yet another form of traditional customer service akin to customer service through email, albeit in a more efficient way. Therefore, we propose the following two hypotheses for empirical testing:

Hypothesis 2A: Firms are more likely to respond to customer complaints communicated privately than to complaints communicated publicly.

Hypothesis 2B: Firms are more likely to respond faster to customer complaints communicated privately than to complaints communicated publicly.

To test these two hypotheses, we resort to a randomized field experiment on a popular social media platform where similar complaining messages are communicated to firms through either a public or a private channel.

The rest of the paper is organized as follows: after briefly reviewing the literature in the next section, we first present the natural experiment to test Hypotheses $1 \mathrm{~A}$ and $1 \mathrm{~B}$. Then, we present the randomized field experiment to test Hypotheses 2A and 2B. Finally, we conclude the paper by summarizing the contributions and limitations of this research.

\section{Literature Review}

Our research is broadly related to the vast literature on consumer complaint behavior and is most closely related to the small stream of literature on customers' choice of complaint channels.

Consumer Complaint Behavior (CCB). Complaints often result from a disparity between consumers' expectations in the pre-purchase stage and disconfirmation in the post-purchase stage [6]. Different causes of product failure may lead to different forms of complaints such as demanding a refund or an exchange for the product, or an apology from the firm [10]. Postpurchase complaints include consumer-initiated communication to marketers, their channel members, or public agencies, to obtain remedy or restitution for purchase or usage-related problems [19]. Firms regularly provide services to address complaints and dissatisfaction, and firms' successful remedial actionssuch as providing refund, exchange, or repair-may be able to help retain customers [4]; meanwhile, firms' inappropriate handling of customers' redress can lead to negative word-of-mouth and damage businesses [3]. 
Consumer Complaint Channel. Day and Landon [8] categorized actions by dissatisfied consumers into public actions - e.g., contacting the business to seek redress or pursuing legal actions, and private actionse.g., boycotting the business or warning friends and family. This taxonomy regarding the definition of public and private complaints is largely followed by the literature $([1,13,16,17])$. As is succinctly summarized in Balaji et al. [1], "Under these definitions, public complaints are complaints visible for the service provider to see, while private complaints largely remain undetected by the service provider." The only exceptions we found are Gregoire et al. [11] and Breitsohl et al. [5]. In Gregoire et al. [11], private complaining is implicitly defined as customers voicing their concerns only to firms and public complaining is implicitly defined as customers going beyond firms' borders to alert the public about a service failure episode, which is closest to how we define public voicing and private voicing in the current paper. Mattila and Wirtz [16] expanded Day and Landon [8] and found that customers seeking tangible compensations prefer interactive channels such as face-to-face communication and phone calls, while those seeking to vent their frustration prefer remote channels such as letters and e-mails; Susskind [18] distinguished between complaints directed to management from those directed to line-level employees; Berry et al. [2] explicitly studied the effect of customers' personality on their complaint channel choices. In this paper we consider

\section{Study 1: Natural Experiment}

To understand how customers choose between the public channel and the private channel to communicate with a brand on social media, we exploit a natural experiment where the relative ease of using the private channel is exogenously and dramatically increased. Our empirical strategy relies on an institutional change Twitter made in April 2015: Twitter started to provide the option that allows users to opt in to receive direct messages from anyone, regardless of whether the sender and recipient were following each other. ${ }^{2}$ Specifically, we exploit one exogenous shock generated by Delta Air Line's decision to enable any Twitter user to send direct messages to them, which we refer to as the OpenDM policy, to achieve causal identification. The OpenDM policy can reduce the cost for Twitter users to contact airlines, making DM an attractive customer service and communication channel. Using this shock, we examine

\footnotetext{
${ }^{2}$ https://techcrunch.com/2015/04/20/twitter-now-lets-you-opt-in-toreceive-direct-messages-from-anyone/ (Last access: June 7, 2018)

${ }^{3}$ Note that airlines sometimes post tweets which aim to engage with customers. For example, an airline company might ask customers to tweet their favorite vacation destinations, and customers might tweet
}

whether there is any change in customers' choice of communication channel after airlines' adoption of OpenDM. As airlines sequentially enabled the OpenDM functionality, we are able to causally identify the impact of OpenDM by comparing airlines that just enabled OpenDM with other airlines that did not change their OpenDM setting - note that some airlines had already enabled OpenDM prior to the shocks we observed, and therefore we treat those airlines as the control group. In the sections below we describe the data used in our analysis and our empirical strategy.

\subsection{Data}

We obtain major U.S. airlines' customer tweets data from Jan 1, 2016 to July 21, 2016 through a social media analytics company. We also monitored major U.S. airlines' Twitter accounts from Feb $1^{\text {st }}, 2016$ to June $30^{\text {th }}$, 2016 to see whether and when these airlines enabled the OpenDM functionality. During this period we successfully observed that Delta Air Lines enabled OpenDM on March 31, 2016. The decision to enable OpenDM was made by the airline itself, which is perceived as an exogenous shock to the customers attempting to contact the airlines. At the same time, other major U.S. airlines including United Airlines, American Airlines, and Southwest Airlines kept their OpenDM functionality enabled throughout our observation period. These major U.S. airlines serve as the control group for Delta Air Lines as they operate in similar markets and are comparable in size. Empirically, we use a Difference-in-differences (DID) analysis to examine how the customer tweets sent to Delta Air Lines changed in response to its OpenDM adoption. Specifically, we evaluate the impact of OpenDM from the following perspectives: the changes in percentage of complaint tweets, and the number of tweets received by the airlines.

\subsection{Measures}

As customers and airlines sometimes engage in back and forth conversations over multiple tweets regarding a single issue, we first consolidate tweets into distinct dialogues. Specifically, for each tweet in our data set we are able to see if this tweet is responding to an earlier tweet and, if it is, the ID of the tweet being responded to. We use this information to trace and construct sequences of tweets that belong to the same dialogues between an airline and an individual customer. Overall, our data set contains 770,705 customerinitiated dialogues. ${ }^{3}$

their replies at the airline company. As these airline-initiated dialogues appear to be distinct from dialogues initiated by customers seeking help, we focus only on customer-initiated dialogues in our empirical analysis and exclude all airline-initiated dialogues. 
We adopt a supervised-learning approach to classify whether a given tweet is a complaint or a noncomplaint. Operationally, we hired three annotators to independently label around 3700 randomly selected customer tweets. The inter-rater reliability measure suggests there is a high level of agreement between the three annotators (Fleiss' Kappa $=0.721$ ). We use the labeled data to train a support vector machine (SVM) classifier, which we then use to classify the first tweet of each dialogue in our data set to determine whether a given dialogue is a complaint. SVM is a widely used machine learning method [7] that has demonstrated strong performance in a variety of classification tasks. The SVM classifier's performance is shown in Table 1, suggesting the classification performance is satisfactory. The summary statistics of the main variables are shown in Table 2.

\subsection{Empirical Model}

We treat Delta Air Lines' decision to adopt OpenDM as an exogenous shock to its customers. By treating the OpenDM as an exogenous shock we are assuming that customers are simply reacting to the addition of DM rather than causing Delta to enable OpenDM. This assumption is reasonable because individual customers are unlikely to lead to Delta's adopting OpenDM. Therefore, customer tweets sent to Delta Air Lines are considered to be in the treatment group; meanwhile, since other major U.S. airlines did not change their OpenDM policy during this time period, we treat customer tweets sent to other airlines as the control group. The treatment and control groups allow us to specify a Difference-in-Differences (DiD) model to examine the effect of OpenDM on customers' tweeting behavior. ${ }^{4}$ Specifically, we construct a panel data set where, for each airline, we observe the daily number of tweets this airline received during our observation period. The linear regression function for our DID analysis is as follows:

$$
\begin{aligned}
\mathrm{y}_{j t}=\alpha_{0}+\alpha_{1} * & T_{j} \\
& + \text { After }_{t}+\alpha_{2} * \text { After }_{t}+\delta_{j} \\
& \text { Week }_{t}+\text { DayofWee }_{t}+\epsilon_{j t}, \\
& \epsilon_{j t} \sim N\left(0, \sigma_{1}\right)
\end{aligned}
$$

where $\mathrm{y}_{j t}$ is the logarithm-transformed number of tweets airline $\mathrm{j}$ received on day t. $T_{j}$ is a dummy variable equal to 1 if airline $\mathrm{j}$ is Delta Air Lines. After ${ }_{t}$ is a dummy variable ${ }^{5}$ indicating whether day $t$ is after Delta Air Lines' OpenDM adoption date. $\delta_{j}$, Week $k_{t}$, and Dayo fWeek $k_{t}$ are airline specific, week specific, and day of week fixed effects.

\footnotetext{
${ }^{4}$ We conducted a relative time model analysis, and the results showed that there is no significant pre-treatment differences between the treatment and control groups, suggesting our choice of control group is appropriate.
}

\subsection{Empirical Results}

We use data three months before Delta's OpenDM shock to three months after the shock for our empirical analysis. The DiD analysis results are shown in

Table 3. From Column 1 of

Table 3 we can see that the tweets Delta Air Lines received after allowing OpenDM are significantly more likely to be complaints. Interestingly, Column 4 of

Table 3 shows that the number of non-complaint tweets decreased significantly after Delta Air Line's OpenDM shock, while the number of complaint tweets did not change significantly, as shown in Column 3 of

Table 3. This indicates that after the introduction of an alternative communication channel, customers who complain about airline companies tend to keep using the public channel. Only those tweets looking for information seem to shift to the private channel. As a result, the percentage of complaint tweets among all tweets sent to the airlines increased after the airlines enabled OpenDM, as can be seen in Column 5 of

Table 3. This indicates that, despite airlines' attempt to encourage customers to complain privately by enabling OpenDM, customers are "stubborn" and still choose to complain publicly.

\section{Study 2: Field Experiment}

One advantage for customers to seek customer service on social media is the fact it is by default public-customers are able to communicate with companies directly and openly on social media platforms such as Twitter such that other users are also able to see how companies handle their customer service. Therefore, the addition of direct message (DM) as an alternative communication channel is an interesting departure from the more typical social media communication in the sense that DM takes place in private, so that customers can provide more personal information while companies do not face as much scrutiny from the general public. As such, DM resembles the more traditional way of customer service where complaints are generally invisible to the public. From the company's perspective, it might be beneficial to encourage customers to compliment in public and complain in private, so the public sentiment stays high, which creates a positive word-of-mouth, and complaints can be resolved privately. However, since complaints sent through the private channel are kept out of the public eye, companies might be less inclined to exert effort in resolving issues. If companies' motivation to

\footnotetext{
${ }^{5}$ This dummy variable is included along with week dummies and day of week dummies because the adoption day is on a Thursday, rather than a Sunday.
} 
encourage private channel is to reduce potentially negative sentiment, then we can expect companies to have different response strategies for complaints versus non-complaints, and public channel versus private channel. To understand companies' motivation to encourage the private channel, we conduct a randomized field experiment on a popular social media platform, which allows us to examine how companies prioritize their responses to customers seeking help through the public channel and the private channel. This experiment will help us better understand companies' response strategies and their motivation to provide the private channel as an alternative communication channel.

\subsection{Experiment Design}

Our experiment consists of four experimental conditions (C1-C4) based on the message typecomplaint or non-complaint - and the communication channel-public or private. The conditions are listed in Table 4. These four conditions will help us understand how companies respond to complaint versus noncomplaint messages sent through public versus private channels.

Our experiment uses a popular social media platform and eight B2C companies. We selected 100 non-complaint messages and 100 complaint messages from a data set of historical messages collected from the social media platform. Out of the 100 non-complaint messages we randomly selected 50 of them to create non-complaint messages to be sent privately $(\mathrm{C} 1)$, and the rest 50 to send publicly (C3). Similarly, out of the 100 complaint messages we randomly selected 50 of them to create complaint messages to be sent through the private channel (C2) and the rest 50 to be sent through the public channel (C4). For each message we manually created eight versions so that all eight companies would receive essentially identical messages except for the company's name. This helps ensure that all eight companies receive the same treatments.

To operationalize the above experiment design as cleanly as possible, we enlisted 800 existing accounts on this social media platform to send messages. As we planned to send 200 messages (50 messages for each experimental condition) to each of the 8 companies, we utilized all 800 accounts and made sure that each account only sent one public message to a company and one private message to a different company, so companies would not suspect the authenticity of the social media accounts used and the messages sent. The assignments of social media accounts to messages and

\footnotetext{
${ }^{6}$ We conduct t-tests and linear regressions to explore if the delivery rates vary among different types of messages.

${ }^{7}$ Social media customer service is considered time sensitive. In our experiment data, if responded, a company's response time is within
}

those accounts to companies were all randomly determined.

\subsection{Experiment Schedule}

To control for potential time effects such as any patterns across different days of a week and different hours of a day, we developed a randomized messagesending schedule as follows:

1. A week is divided into thirty-minute blocks, resulting in 336 thirty-minute blocks in one week.

2. For each thirty-minute block we generated a random integer between 0 and 1799 to represent the specific second within the thirty-minute block a message should be sent. This resulted in 336 candidate time points within one week.

3. For each company, since we planned on sending 200 messages throughout the experiment, we randomly picked 200 out of the 336 candidate time points as the final messaging time to send these 200 messages. The ordering of these 200 messages were also randomized, ensuring that a company received a sequence of treatment conditions in a random order.

4. We repeated steps 1 - 3 above for each company. Since each company required 200 messaging times, we randomly generated a total of 1600 time points. Due to some technical consideration, these 1600 time points were randomly generated in a way that none of the 1600 messages shared the exact same messaging time.

We followed our message-sending schedule to send a total of 1600 messages to the eight companies, out of which, 1533 messages were successfully delivered in the end. Note that there is no significant difference in the delivery success rates across the four experiment conditions. ${ }^{6}$ For each of the successfully delivered messages, we kept track of whether or not the company replied to it; ${ }^{7}$ if replied, we also recorded the duration between our message time and the company's response time.

\subsection{Experiment Results}

Among the 1533 messages delivered, 1234 were replied by the eight companies. The reply ratio for each treatment condition is shown in Table 5. We can see that complaints sent publicly have a lower reply ratio, while the other three conditions have similar and higher reply ratios.

We formally compare these reply ratios by t-tests, shown in Table 6. We can see that in both t-test with equal variance and t-test without equal variance, public complaint messages have a lower reply ratio than

half an hour. Therefore, we marked a message as 'not replied' if the company did not respond to the message within 5 days. 
private complaint messages. Specifically, the private complaint messages are roughly $17 \%$ more likely to be replied to compared with public complaints. We also find that public complaint messages have a lower reply ratio than public non-complaint messages (noncomplaint messages sent via the public channel are $18 \%$ more likely to be replied to compared with complaint messages sent by the public channel.)

We then analyze the experiment data using linear probability, logit, and probit models, shown in Table 7. The dependent variable in all models is whether a message was replied to. $\mathrm{C} 2, \mathrm{C} 3$, and $\mathrm{C} 4$ are dummy variables indicating the message's treatment condition. Control variables include the total number of public messages the companies received within the same hour our message was sent (log_received), the inferred gender of each social media account (ismale) used to send the message based on each social media account's displayed name, time-fixed effects including the hour of day and the day of week, and company-fixed effects. The results across different model specifications all show that there is no significant differences in reply ratio among conditions $\mathrm{C} 1, \mathrm{C} 2$, and $\mathrm{C} 3$, while messages in $\mathrm{C} 4$ are significantly less likely to be replied to, according to the results of $F$ tests. This finding suggests that companies tend to discriminate against customers who voice their complaints using the public channel. As expected, we also find that the overall response rate goes down as the number of public messages received by a company (log_received) increases.

Among messages that were replied to, we also analyze the duration between the time a message was sent and the time the message was responded by the company, measured in seconds. The duration for each treatment condition is shown in Table 8, and the corresponding two-sample t-tests are shown in Table 9. The results show that companies responded to public complaints significantly slower than they responded to private complaints, which further suggest that companies prioritize private complaints over public complaints.

We also specified regression models to analyze the reply time for the 1234 messages that were replied to. Specifically, we use OLS with natural-logarithmtransformed reply time as the dependent variable; The regression results are shown in Table 10 . We can see that companies responded to private complaints faster than all other treatment condition, again suggesting companies prioritize private complaints over public complaints.

Overall, our field experiment results show that companies are less likely to respond to public complaints; even when replied, the response time associated with public complaints are longer. Meanwhile, we did not observe any difference in reply ratio between public non-complaint messages and private non-complaint messages, nor did we observe any difference in reply time between public noncomplaint messages and private non-complaint messages. This suggests that the different patterns we observed in reply ratio between public complaints and private complaints are not driven by the communication channel itself; rather, companies appeared to have strategically avoided or delayed responding to public complaints. One potential explanation for this strategy is that companies might be trying to discourage customers from complaining publicly by delaying or avoiding responses, in the hope that customers would be motivated to utilize the private channel for complaints. At the same time, companies also try to shorten the reply time for private complaints, as shown in Table 10, so customers might find it beneficial to adopt the private channel for complaints. The companies' strategy, if successful, will help companies maintain a positive sentiment on social media platforms. In addition, by not replying to public complaints, companies can avoid further publicizing negative sentiments because on this social media platform, only public complaints that are replied to will appear on the company's home page. In other words, customers' public complaint will not be immediately visible to other customers perusing the company's home page if the public complaints are left un-replied, so by not replying to complaint messages companies can reduce the size of the negative word-ofmouth. In conclusion, our experiment results suggest that companies might be trying to convert the more public social media customer service back to the traditional style where complaints are made in private, so as to avoid the risk of negative word-of-mouth.

\section{Conclusion}

In this paper, we studied the choice between public and private channels of customer service interaction on social media, both from customers' and brands' perspectives. Through a natural experiment, we found that complaining customers prefer to do so publicly while some non-complaining customers prefer to communicate privately. Through a randomized field experiment, we found that firms prioritize complaints sent through the private channel over complaints sent through the public channel, as shown in the lower response rate and longer response time for public complaints. Such a prioritization is absent for noncomplaint messages. Hence, we conclude that firms, being aware of the risk of subjecting its customer service under public scrutiny, prefer complaints communicated privately and seem to nudge customers towards switching back to the traditional mode of customer service. The diverging preferences of the two sides towards open voice and private message suggests a tug 
of war between the traditional delivery of customer service featuring brand control and social media customer service featuring transparency and openness.

Our analysis shows that firms' social media strategy seems to focus on an image-first mindset, where firms attempt to manage their image by maintaining a high public sentiment on social media sites. This can lead to their unwillingness to respond to negative contents so as not to further publicize their service failures. However, such image-first mindset does not seem sustainable in the current social media era as customers begin to demand accountability and transparency online and prefer voicing complaints publicly. This suggests that an image-first mindset leads to more harm than good for firms. Therefore, instead of an image-first mindset, we recommend that firms adopt a solution-first mindset, where firms strive to address customer complaints regardless of the communication channel. A solution-first mindset encourages firms to address complaints in a timely manner, minimizing the risk of additional complaints. Furthermore, such instances of successful complaint resolution can be observed by the public and might even improve their public image. We therefore believe that the solutionfirst mindset will ultimately be advantageous to firms' successful social media complaint management.

As the first study revealing this interesting hidden phenomenon, we believe this paper significantly contributes to our understanding of the promises and challenges of social media customer service.

\section{Reference}

[1] Balaji, M. S., Subhash Jha, and Marla B. Royne. "Customer e-complaining behaviours using social media." The Service Industries Journal 35, no. 11-12 (2015): 633-654.

[2] Berry, Riley, Sarah Tanford, Rhonda Montgomery, and Alison J. Green. "How we complain: the effect of personality on consumer complaint channels." Journal of Hospitality \& Tourism Research 42.1 (2018): 74-101.

[3] Blodgett, Jeffrey G., Kirk L. Wakefield, and James H. Barnes. "The effects of customer service on consumer complaining behavior." Journal of Services Marketing 9.4 (1995): 31-42.

[4] Bolfing, Claire P. "How do customers express dissatisfaction and what can service marketers do about it?." Journal of Services Marketing 3.2 (1989): 5-23.

[5] Breitsohl, Jan, Marwan Khammash, and Gareth Griffiths. "Online complaint communication strategy: an integrated management framework for e-businesses." Handbook of
Strategic e-Business Management. Springer, Berlin, Heidelberg, 2014. 907-933.

[6] Cho, Yooncheong, Il Im, Starr Roxanne Hiltz, and Jerry Fjermestad. "Causes and outcomes of online customer complaining behavior: Implications for customer relationship management (CRM)." AMCIS 2001 Proceedings (2001): 175.

[7] Cortes, Corinna, and Vladimir Vapnik. "Support-vector networks." Machine learning 20.3 (1995): 273-297.

[8] Day, Ralph L., and E. Laird Landon. "Toward a theory of consumer complaining behavior." Consumer and industrial buying behavior 95 (1977): 425-437.

[9] Deutsch, Morton. 1985. Distributive Justice: A SocialPsychological Perspective, Yale University Press.

[10] Folkes, Valerie S. "Consumer reactions to product failure: An attributional approach." Journal of Consumer Research 10.4 (1984): 398-409.

[11] Grégoire, Yany, Thomas M. Tripp, and Renaud Legoux. "When customer love turns into lasting hate: The effects of relationship strength and time on customer revenge and avoidance." Journal of Marketing 73. 6 (2009): 18-32.

[12] Gunarathne, Priyanga, Huaxia Rui, and Abraham Seidmann. "Differential Customer Treatment in the Airline Industry." MIS Quarterly (2018), forthcoming.

[13] Harrison-Walker, L. Jean. "The measurement of word-ofmouth communication and an investigation of service quality and customer commitment as potential antecedents." Journal of Service Research 4.1 (2001): 60-75.

[14] He, Shu, Huaxia Rui, and Andrew B. Whinston. 2017. "Social Media Strategies in Product-Harm Crises." Information Systems Research 29.2 (2018): 362-380.

[15] Hirschman, Albert O. Exit, voice, and loyalty: Responses to decline in firms, organizations, and states. Vol. 25. Harvard university press, 1970.

[16] Mattila, Anna S., and Jochen Wirtz. "Consumer complaining to firms: the determinants of channel choice." Journal of Services Marketing 18.2 (2004): 147-155.

[17] Singh, Jagdip. "Consumer complaint intentions and behavior: definitional and taxonomical issues." Journal of Marketing (1988): 93-107.

[18] Susskind, Alex M. An examination of guest complaints and complaint communication channels: the medium does matter!. Cornell University, School of Hotel Administration, The Center for Hospitality Research, 2006.

[19] Westbrook, Robert A. "Product/consumption-based affective responses and postpurchase processes." Journal of Marketing Research (1987): 258-270. 
Tables

Table 1. Performance of the SVM classifier on 3700 tweets using 10-fold vross validation

\begin{tabular}{|c|c|c|c|c|c|c|c|c|}
\hline & Accuracy & $\begin{array}{l}\text { Precision } \\
(+)\end{array}$ & $\begin{array}{r}\text { Recall } \\
(+)\end{array}$ & F1 & $\begin{array}{c}\text { Precision } \\
(-)\end{array}$ & $\begin{array}{r}\text { Recall } \\
(-)\end{array}$ & $\begin{array}{ll}\text { F1 } & \\
\end{array}$ & AUC \\
\hline Fold 1 & 0.80 & 0.68 & 0.70 & 0.69 & 0.85 & 0.84 & 0.84 & 0.77 \\
\hline Fold 2 & 0.78 & 0.77 & 0.66 & 0.71 & 0.78 & 0.86 & 0.82 & 0.77 \\
\hline Fold 3 & 0.76 & 0.78 & 0.63 & 0.70 & 0.75 & 0.87 & 0.81 & 0.77 \\
\hline Fold 4 & 0.77 & 0.80 & 0.62 & 0.70 & 0.76 & 0.89 & 0.82 & 0.78 \\
\hline Fold 5 & 0.81 & 0.81 & 0.69 & 0.75 & 0.81 & 0.89 & 0.85 & 0.81 \\
\hline Fold 6 & 0.76 & 0.83 & 0.61 & 0.70 & 0.73 & 0.90 & 0.81 & 0.78 \\
\hline Fold 7 & 0.81 & 0.78 & 0.65 & 0.71 & 0.82 & 0.90 & 0.86 & 0.80 \\
\hline Fold 8 & 0.71 & 0.74 & 0.50 & 0.60 & 0.69 & 0.87 & 0.77 & 0.72 \\
\hline Fold 9 & 0.79 & 0.75 & 0.62 & 0.68 & 0.81 & 0.89 & 0.85 & 0.78 \\
\hline Fold 10 & 0.82 & 0.77 & 0.67 & 0.72 & 0.84 & 0.90 & 0.87 & 0.81 \\
\hline Average & 0.78 & 0.77 & 0.64 & 0.70 & 0.78 & 0.88 & 0.83 & $\overline{0.78}$ \\
\hline
\end{tabular}

Note: This table reports the SVM classifier's performance. The (+) symbol represents the positive case (complaints), and the (-) symbol represents the negative case (non-complaints).

Table 2. Summary statistics

\begin{tabular}{|l|l|l|l|l|l|l|}
\hline Variables & Description & obs & mean & s.d. & $\max$ & $\min$ \\
\hline If_complaint & $\begin{array}{l}\text { If the first tweet in the dialogue } \\
\text { is a complaint or not }\end{array}$ & 770,705 & 0.556 & 0.497 & 1 & 0 \\
\hline Log_followers & $\begin{array}{l}\text { Log(number of followers for } \\
\text { the user who initiated the } \\
\text { dialogue) }\end{array}$ & 770,705 & 5.559 & 2.258 & 17.418 & 0 \\
\hline Num_tweets & $\begin{array}{l}\text { Daily number of tweets } \\
\text { received }\end{array}$ & 728 & 1058.661 & 599.792 & 8980 & 305 \\
\hline Num_complaint & $\begin{array}{l}\text { Daily number of complaint } \\
\text { tweets received }\end{array}$ & 728 & 588.937 & 365.461 & 3207 & 103 \\
\hline $\begin{array}{l}\text { Num_noncomplai } \\
\text { nt }\end{array}$ & $\begin{array}{l}\text { Daily number of non- } \\
\text { complaint tweets received }\end{array}$ & 728 & 469.724 & 382.607 & 7466 & 176 \\
\hline
\end{tabular}

Table 3. Main estimation results for Delta Air Lines

\begin{tabular}{|c|c|c|c|c|c|}
\hline & Dialogue & \multicolumn{3}{|c|}{ Daily number of dialogues (log) } & \multirow{2}{*}{$\begin{array}{l}\text { Proportion of } \\
\text { Complaint } \\
\text { Tweets }\end{array}$} \\
\hline & If_complaint & All & Complaint & Non_complaint & \\
\hline \multirow[t]{2}{*}{ Treatment*after } & $0.351 * * *$ & -0.0612 & 0.0366 & $-0.192 * * *$ & $0.0549 * * *$ \\
\hline & $(0.0921)$ & $(0.0478)$ & $(0.0518)$ & $(0.0596)$ & $(0.0120)$ \\
\hline \multirow[t]{2}{*}{ after } & -0.0166 & -0.0252 & -0.0614 & 0.0194 & $-0.0195 * *$ \\
\hline & $(0.0927)$ & $(0.0482)$ & $(0.0502)$ & $(0.0521)$ & $(0.00879)$ \\
\hline Weekday fixed effects & yes & yes & yes & yes & yes \\
\hline Week fixed effects & yes & yes & yes & yes & yes \\
\hline Airlines fixed effects & yes & yes & yes & yes & yes \\
\hline \multirow[t]{2}{*}{ Constant } & $1.120 * * *$ & $7.203 * * *$ & $6.947 * * *$ & $5.815 * * *$ & $0.760 * * *$ \\
\hline & $(0.0526)$ & $(0.0376)$ & $(0.0450)$ & $(0.0449)$ & $(0.0120)$ \\
\hline Obs & 770,705 & 728 & 728 & 728 & 728 \\
\hline
\end{tabular}


Table 4. Experiment design

\begin{tabular}{|l|l|l|}
\hline & non-complaint & complaint \\
\hline private channel & private noncomplaints $(\mathrm{C} 1)$ & private complaints $(\mathrm{C} 2)$ \\
\hline public channel & public noncomplaints $(\mathrm{C} 3)$ & public complaints $(\mathrm{C} 4)$ \\
\hline
\end{tabular}

Table 5. Reply ratio for each treatment condition

\begin{tabular}{|l|l|l|}
\hline reply ratio (\# of messages) & non-complaint & complaint \\
\hline private channel & $0.8560(389)$ & $0.8241(381)$ \\
\hline public channel & $0.8329(389)$ & $0.7032(374)$ \\
\hline
\end{tabular}

Table 6. Results of two-sample T-tests

\begin{tabular}{|l|l|l|}
\hline & T statistic \\
\hline & With equal variances & Without equal variances \\
\hline complaints: & $-0.1209^{* * *}$ & $-0.1209^{* * *}$ \\
mean(public channel)-mean(private channel) & $(-3.949)$ & $(-3.942)$ \\
\hline non-complaints: & -0.02314 & -0.02314 \\
mean(public channel)-mean(private channel) & $(-0.8897)$ & $(-0.8897)$ \\
\hline private channel: & 0.02642 & 0.02642 \\
mean(non-complaint)-mean(complaint) & $(1.207)$ & $(1.206)$ \\
\hline public channel: & $0.1297^{* * *}$ & $0.1297^{* * *}$ \\
mean(non-complaint)-mean(complaint) & $(4.297)$ & $(4.280)$ \\
\hline \multicolumn{2}{|c|}{${ }^{* * *} \mathrm{p}<0.01,{ }^{* *} \mathrm{p}<0.05,{ }^{*} \mathrm{p}<0.1$} & \\
\hline
\end{tabular}

Table 7. Regression analysis on companies' reply decision

\begin{tabular}{|c|c|c|c|}
\hline & \multicolumn{3}{|l|}{ If_reply } \\
\hline & LPM & logit & probit \\
\hline \multirow{2}{*}{$\mathrm{C} 2$} & -0.0328 & -0.270 & -0.149 \\
\hline & $(0.0258)$ & $(0.204)$ & $(0.113)$ \\
\hline \multirow[t]{2}{*}{ C3 } & -0.0226 & -0.179 & -0.106 \\
\hline & $(0.0255)$ & $(0.206)$ & $(0.115)$ \\
\hline \multirow[t]{2}{*}{$\mathrm{C} 4$} & $-0.148 * * *$ & $-0.965 * * *$ & $-0.564 * * *$ \\
\hline & $(0.0287)$ & $(0.191)$ & $(0.109)$ \\
\hline \multirow[t]{2}{*}{ log_received } & $-0.0479 * * *$ & $-0.344 * * *$ & $-0.191 * * *$ \\
\hline & $(0.0128)$ & $(0.0945)$ & $(0.0528)$ \\
\hline \multirow[t]{2}{*}{ ismale } & -0.0284 & -0.198 & -0.110 \\
\hline & $(0.0196)$ & $(0.138)$ & $(0.0782)$ \\
\hline Time fixed effects & yes & yes & yes \\
\hline Company fixed effects & yes & yes & yes \\
\hline \multirow[t]{2}{*}{ constant } & $1.214 * * *$ & $4.699 * * *$ & $2.642 * * *$ \\
\hline & $(0.0746)$ & $(0.607)$ & $(0.332)$ \\
\hline Obs & 1,533 & 1,533 & 1,533 \\
\hline F test: $\mathrm{C} 2=\mathrm{C} 4$ & $15.03 * * *$ & $14.26 * * *$ & $15.46^{* * *}$ \\
\hline F test: $\mathrm{C} 3=\mathrm{C} 4$ & $181.3 * * *$ & $17.87 * * *$ & $18.12 * * *$ \\
\hline
\end{tabular}


Table 8. Reply time for each treatment condition

\begin{tabular}{|l|l|l|}
\hline Log reply time in seconds (\# of messages) & non-complaint & complaint \\
\hline private channel & $7.045(333)$ & $6.823(314)$ \\
\hline public channel & $7.040(324)$ & $7.125(263)$ \\
\hline
\end{tabular}

Table 9. Results of two-sample T-tests for reply time

\begin{tabular}{|l|l|l|}
\hline \multicolumn{2}{|c|}{} & \multicolumn{2}{|c|}{ T statistic } \\
\hline Log(reply time) & With equal variances & Without equal variances \\
\hline complaints: & $0.3013^{* *}$ & $0.3013^{* *}$ \\
mean(public channel)-mean(private channel) & $(1.834)$ & $(1.838)$ \\
\hline non-complaints: & -0.04481 & -0.04481 \\
mean(public channel)-mean(private channel) & $(-0.0275)$ & $(-0.0275)$ \\
\hline private channel: & 0.2215 & 0.2215 \\
mean(non-complaint)-mean(complaint) & $(1.376)$ & $(1.379)$ \\
\hline public channel: & -0.08424 & -0.08424 \\
mean(non-complaint)-mean(complaint) & $(-0.5025)$ & $(-0.5062)$ \\
\hline
\end{tabular}

${ }^{* * *} p<0.01,{ }^{* *} p<0.05,{ }^{*} p<0.1$

Table 10. Regression analysis on reply time

\begin{tabular}{|c|c|l|}
\hline & Reply time & OLS \\
\hline & $\begin{array}{c}\text { OLS (natural log } \\
\text { transformed) }\end{array}$ & $-2644.34 * *$ \\
\hline C2 & $-0.240^{*} *$ & $(1350.44)$ \\
\hline C3 & $(0.101)$ & 1909.28 \\
\hline & 0.00973 & $(2407.70)$ \\
\hline C4 & $(0.104)$ & -2168.39 \\
\hline & 0.0169 & $(1388.87)$ \\
\hline log_received & $(0.111)$ & $3558.16 * *$ \\
\hline & $0.192^{* * *}$ & $(1532.45)$ \\
\hline ismale & $(0.0508)$ & 1212.45 \\
\hline & -0.0810 & $(1455.04)$ \\
\hline Time fixed effects & $(0.0774)$ & yes \\
\hline Company fixed effects & yes & yes \\
\hline constant & $6.252^{* * *}$ & $-17374.2 * *$ \\
\hline & $(0.290)$ & $(8417.65)$ \\
\hline Obs & 1,234 & 1,234 \\
\hline
\end{tabular}

